\title{
TIG 溶接におけるプール表面温度の計測*
}

一紫外線放射測温法の開発 (第 1 報) -

\author{
岡垣内俊成**, 黄地 尚義***, 宮坂 史和***
}

UV Radiation Thermometry of TIG Weld Pool*

- Development of UV Radiation Thermometry (Report 1)-

by OKAGAITO Toshinari**, OHJI Takayoshi*** and MIYASAKA Fumikazu***

\begin{abstract}
The problem of emissivity change on metal surface complicates the temperature measurement of molten pools in infrared (IR) radiation thermometry. Therefore, an emissivity correction is one of the most important subjects in IR radiation thermometry. The objective of the present investigation is to develop an ultraviolet (UV) radiation thermometry, which is an emissivity correction free method.

According to the Planck's law of radiation, it is evident that the effect of temperature on the spectral radiance is greater at the shorter wavelength, and radiation thermometry in UV range is expected to reduce the error caused by the emissivity change. Generally, the radiation energy in UV range is lower than that in IR range at the same temperature. A measurement system that is sensitive to the UV radiation has been developed in the present work. The system consists of an image intensifier, and multiple optical band-pass filters.

In the present paper, two-dimensional temperature distribution on TIG weld pool has been measured by using the developed UV radiation thermometer. It is made clear that the luminance temperature distributions measured by IR and UV range are quite different, and the surface temperature on molten pool is affected by sulfur concentration in the material.
\end{abstract}

Key Words: Ultraviolet, Infrared, Thermal radiation, Emissivity, TIG, Molten pool, Temperature distribution, SUS304, Sulfur

\section{1. 緒言}

放射測温法は, 非接触の温度計測を可能とする計測方法で ある. 現在実用化されている放射温度計には, 近赤外線, 遠 赤外線を計測するものがある. 赤外線放射温度計は, 産業の 各分野で広く使用されている.

しかしながら赤外線放射測温法には, 計測対象物表面の放 射率が変わることによって, 計測される温度に大きな違いが 現れるという問題がある. その上, この傾向は高温になった 場合により顕著となるため, 赤外線放射測温法を高温計測の 手段として使用するには限界がある。

とくに, アーク溶接時の溶融池表面には液相金属・固相金 属・酸化物等が存在しており, これらの分布が時間によって 変化する. 赤外線放射温度計では, 放射率の影響を強く受け てしまうため, 溶融池温度場の計測は難しい.

筆者らは, 上記の問題を回避する目的で計測波長を紫外域 にとる, 紫外線放射測温法を提案・検討してきた. 紫外線放 射測温法は, 可視光よりも波長の短い, 紫外線を温度計測に 利用することにより, 赤外線を使った従来方式に比べ, 放射

\footnotetext{
*原稿受付 平成 15 年 5 月 6 日

**学生員 大阪大学大学院工学研究科 Student Member, Osaka University

***正 員 大阪大学大学院工学研究科 Member, Osaka University
}

率による影響を格段に小さくできる計測方法である.

本稿では, 新しく開発した紫外線と赤外線での同時計測が 可能な測温装置による, アーク溶接時のプール表面温度を計 測した結果について述べる.

\section{2. 紫外線放射測温法の原理 ${ }^{2-5)}$}

放射測温法は, 物体から放射されるエネルギーを計測する ことで温度を推定する方法である。

黒体は(1)式のプランクの放射則に従い, 温度に応じた波長 一強度パターンを持った放射エネルギーを放出している。

$$
L(\lambda, T)=\frac{2 c_{1}}{\lambda^{5}} \cdot \frac{1}{\exp \left(c_{2} / \lambda T\right)^{-1}}
$$

ただし， $c_{1}=5.9548 \times 10^{-17}\left[\mathrm{~W} \cdot \mathrm{m}^{2}\right], c_{2}=0.014388[\mathrm{~m} \cdot \mathrm{K}]$, $\lambda$ : 波長 $[\mathrm{m}], T:$ 温度 $[\mathrm{K}]$ である.

しかしながら, 実際の物体の放射エネルギーはこれよりも 低くなる. 物体の真温度 $T$ と輝度温度 $S$ の関係は, 放射率 $\varepsilon$ を用いて，(2)式のように表すことができる．なお，放射率と は十分に厚い物体における吸収率に等しく, 黒体で 1 , 鏡面 で 0 となる.

$$
L(\lambda, S)=\varepsilon(\lambda, T) L(\lambda, T)
$$

(1)，(2)式から，放射率が既知の物体の放射エネルギーを計 測することで物体表面の真の温度を知ることができる. Fig. $1^{1)}$ に, インコネルの放射率変動について示した.一般に, 金属に限らず，物体の放射率は表面状態・温度・波長により 


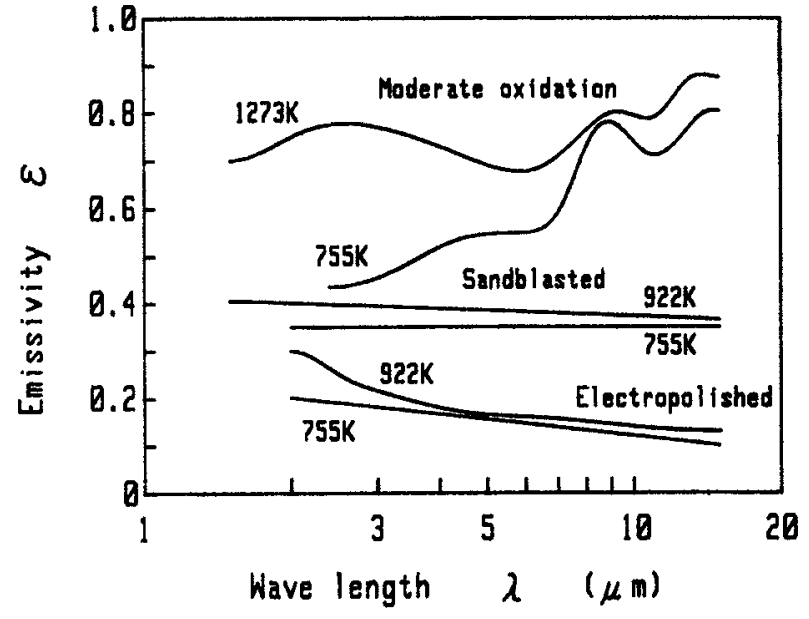

Fig. 1 Spectral emissivity of Inconel. ${ }^{1}$

変化すると言われており，その予測および計測は困難である. 次に, 放射率が放射温度計測に及ぼす影響について述べる. まず，(1)，(2)式から(3)式を得る.

$$
S=\frac{c_{2}}{\lambda} \cdot \frac{1}{\ln \left[\left\{\exp \left(c_{2} / \lambda T\right)-1\right\} / \varepsilon+1\right.}
$$

(3)式は，計測する波長と対象物表面における放射率が，輝 度温度に及ぼす影響について示している。

この(3)式について,計測波長をそれぞれ赤外線 $(\lambda=4 \mu \mathrm{m})$ と,ここで使用した紫外線 $(\lambda=0.35 \mu \mathrm{m})$ での放射率変化 の影響についてまとめたものを Fig. 2 に示した.

Fig. 2 に見られるように，赤外線での温度計測では，輝度 温度 $S$ は放射率 $\varepsilon の$ 影響を強く受ける。このため, 赤外線放 射測温法では放射率補正が必要であると言えると同時に, 放 射率に曖昧さが含まれた場合には, 計測精度に大きな影響を 受ける。

一方，紫外線の場合には，放射率の影響はほとんど受けな い. 輝度温度 $S$ は，放射率が低くなったとしても真温度 $T$ に
近い值を取るため, 放射率補正が無い場合でも, 比較的正確 な温度計測が期待できる。

このことはまた, 本方式が他の放射エネルギーの変動要因 （放射の指向性，対象物までの距離にともなう減衰等）によ っても，計測誤差が発生しにくいことを示している.

\section{3. 紫外線放射測温装置}

一般的な放射温度計では赤外線を計測に利用するのに対 して，本方式では計測に紫外線を利用する。

紫外線放射測温法は，紫外域の放射エネルギーが赤外域の 放射エネルギーに比べ極めて微弱である点や, 紫外線に高い 感度を有するセンサを必要としている点などで, 赤外線放射 測温法と異なる.

このため放射紫外線を計測に利用するためには, 特別な計 測系が必要となる. Fig. 3 に，本研究で使用している装置の 概略を示した。

本計測装置は. レンズ系. フィルタユニット，イメージイ ンテンシファイアおよび, CCD カメラで構成されている. フィルタユニットは， $\lambda=0.35 \mu \mathrm{m}$ の光のみを効率よく取り 出すために, 5 枚の紫外線干渉ミラーにより構成されている.

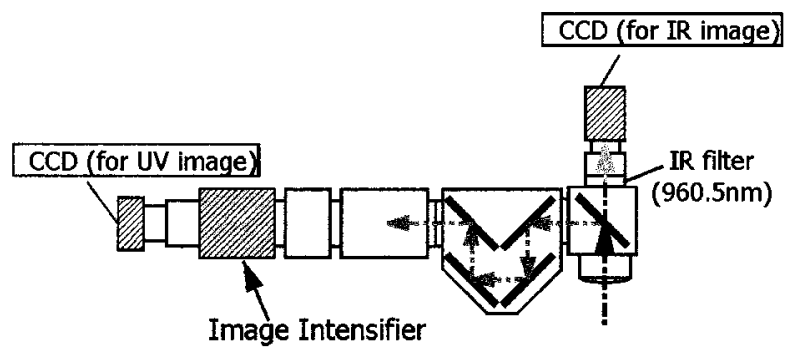

Fig. 3 Experimental apparatus.

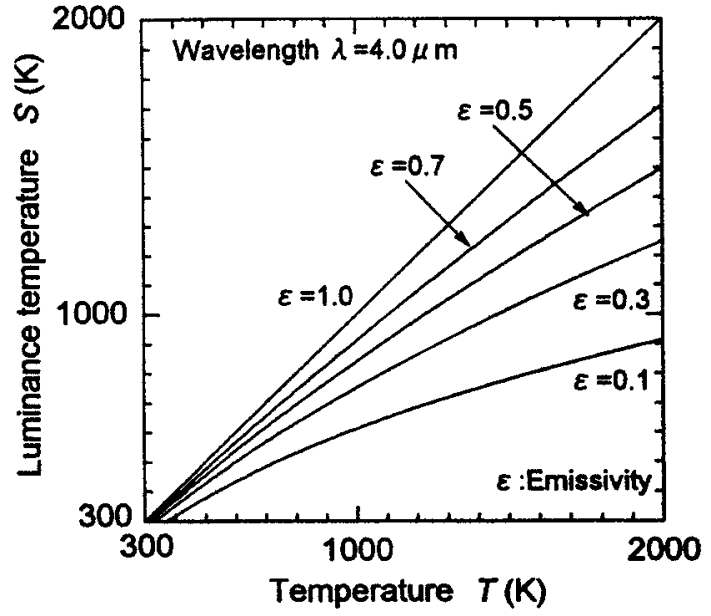

(a) $\lambda=4.0 \mu \mathrm{m}$

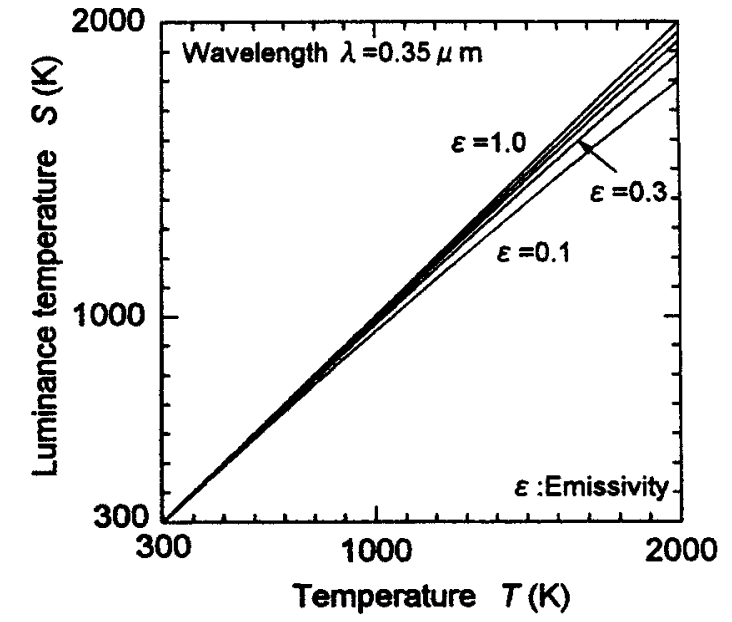

(b) $\lambda=0.35 \mu \mathrm{m}$

Fig. 2 Relation between temperature and luminance temperature. 
なお，一枚目の干渉ミラーを透過した光については， $\lambda=$ $0.96 \mu \mathrm{m}$ の干渉フィルタにより, 紫外像と同時に赤外像を得 ることができるようになっている.

フィルタユニットを透過した紫外光は, 後段のイメージイ ンテンシファイア部で, 約一万倍の増幅と可視光変換がおこ なわれて CCD カメラに記録される.

イメージインテンシファイアとは, 微弱な入射光を光電子 倍増作用により増幅する装置である。この装置により，本来 では通常の CCD 素子では検出が困難な微弱な放射紫外線を 記録できる.

イメージインテンシファイアは, 光の大増幅に伴うノイズ で画質を劣化させるという問題がある. 本研究では, 取得し た画像に対してデジタルフィルタを用いたノイズ除去を行 っている.また, 画像の解像度や最低感度といった, 計測装 置の主要な性能は, この部分により決定される.

なお，本装置は黒体炉を用いて校正を行った。

\section{4. 紫外線放射測温法の特性}

Fig. 4 はSUS304 薄板の静止熱源による溶融池を, それぞ れ赤外線 $(\lambda=0.96 \mu \mathrm{m})$ と紫外線 $(\lambda=0.35 \mu \mathrm{m})$ で同時に 取得した輝度分布画像である。

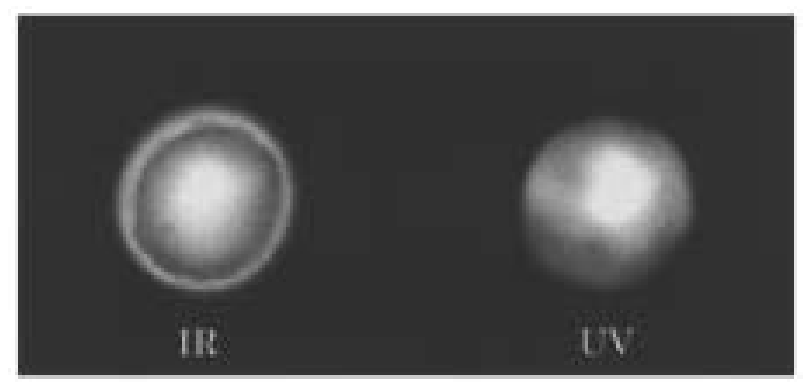

Fig. 4 Luminance images of IR and UV band.
この画像から, 水平断面での輝度温度分布を求めたものが Fig. 5 である.

赤外線を計測に用いた場合には, 溶融池の外側に明るい環 状の領域が現れている。この部分には. 酸化物が存在してお り，放射率が高くなっていると考えられる．また，溶融池中 央部分は比較的清浄な金属表面であると考えられる.この部 分では放射率が低くなり, 輝度温度が真温度にくらべ, 低く 測定されているものと考えられる.

Fig. 4 に見られるとおり，赤外線での計測では，放射率の 補正が無い場合には正しい溶融池温度場を計測することは 難しい. また, 溶融池表面では放射率に分布ができるため, 放射率の補正を正確に行うこともまた, 困難であるといえる. 一方, 紫外光を計測に用いた場合では, 赤外像に見られたよ うな不自然な輝度分布はみられない.

これら二つの波長での見え方の違いから，紫外線放射測温 法は, 赤外線放射測温法に比べて放射率変動の影響が計測值 に現れにくいことが実験的に確かめられた.

\section{5. 溶接温度場の計測}

紫外線放射測温法によって得られた TIG 溶接の温度場を Fig. 6 に示す.この温度場は，ワークの表側（トーチ側）か ら, 溶接電流の切断と同時に溶接トーチを高速で移動させる ことにより取得したものである.

本研究では Fig. 7 のようにトーチを移動させることで，ア 一クから放射される光や, 高温の電極からの放射が温度計測 に影響を与えないようにしている。 なお，計測の際に電極を 移動させる方式については, Giedt らの報告 6) を参考にした.

Giedt らは，瞬間的に電極を溶融池上方に移動させること で, 電極からの放射の影響を受けない状態での溶融池温度を 計測している。これに対して, 本方式では溶融池の真上から 計測を行えるようにするため, 溶接トーチを横方向に移動さ せている。

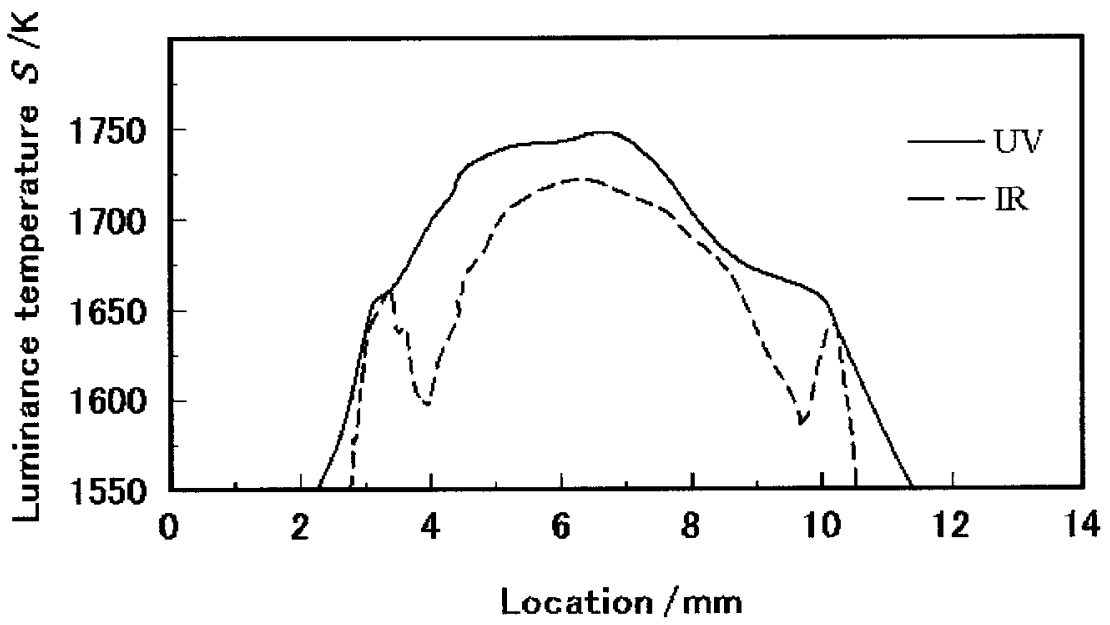

Fig. 5 Comparison of temperature distributions between IR and UV. 


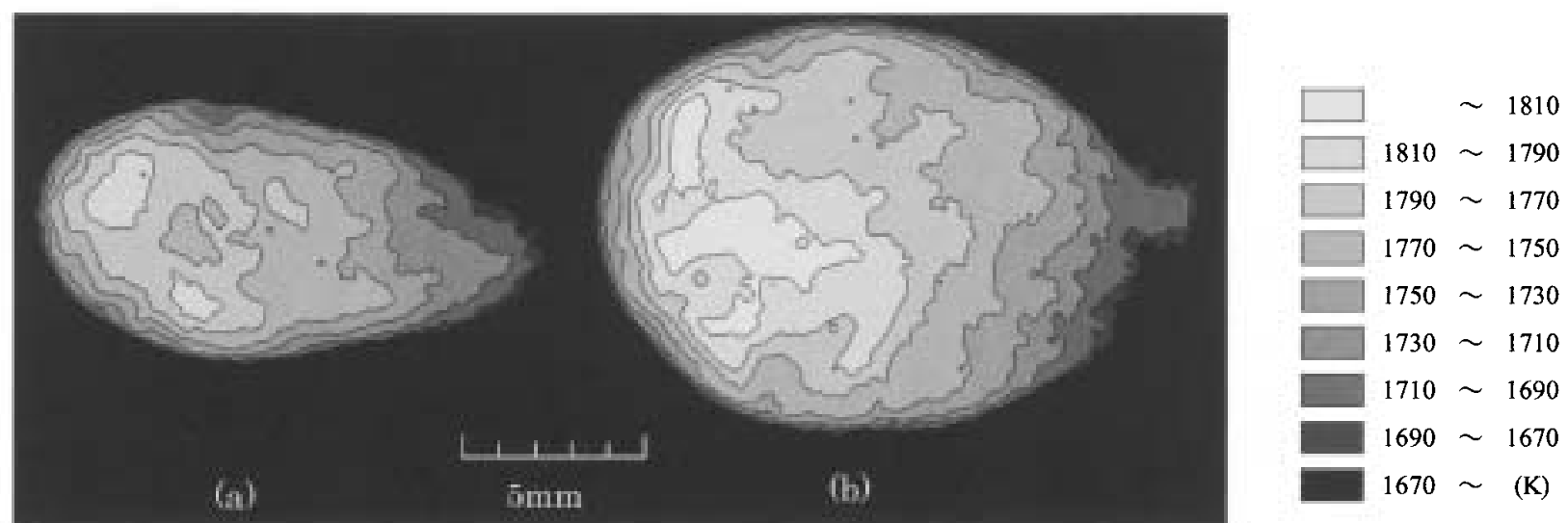

Fig. $6 \mathrm{UV}$ thermal images of metal pool $\left(1.5 \mathrm{mmt} \mathrm{SUS304}, I=100 \mathrm{~A}(\mathrm{a}), 150 \mathrm{~A}(\mathrm{~b})\right.$, Exposure $120 \mathrm{~ms}$, Arc length $3 \mathrm{~mm}, v=4 \times 10^{-3}$ $\mathrm{m} / \mathrm{s})$.

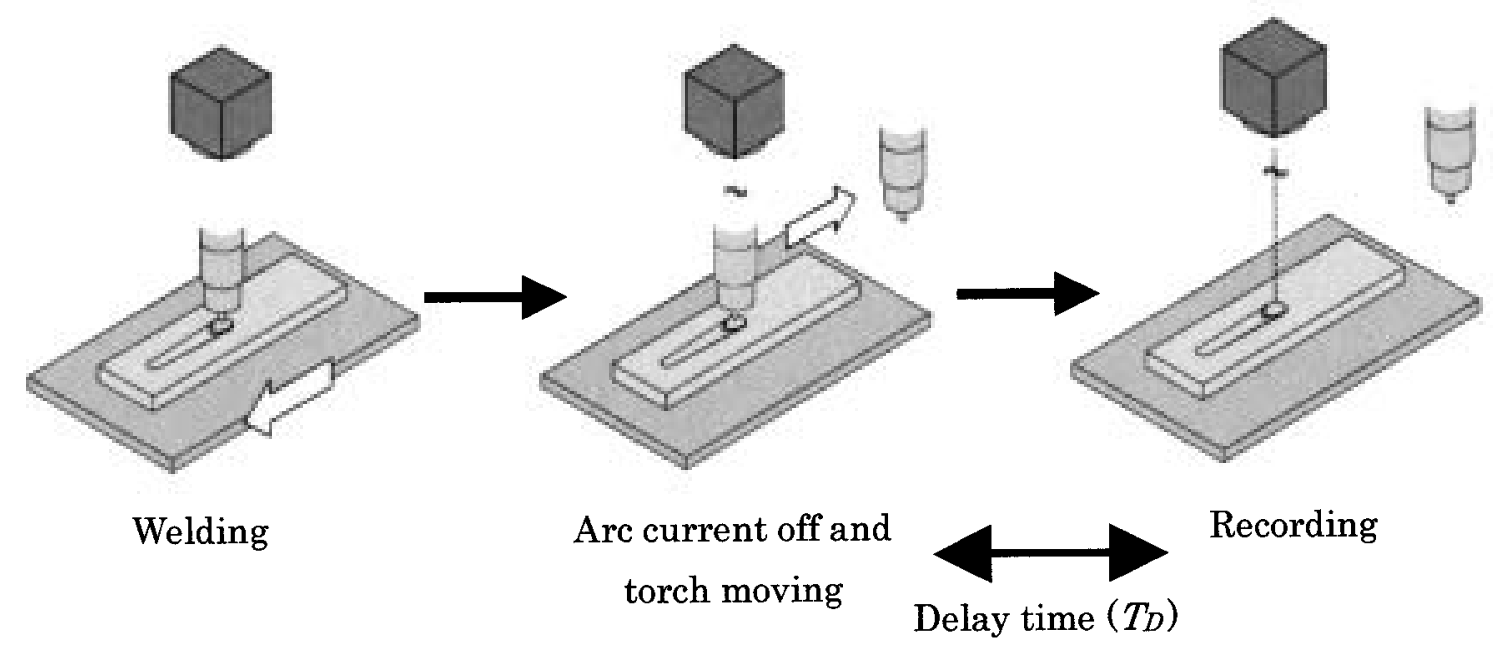

Fig. 7 Measurement equipment and delay time.

なお，実験に用いた装置では，溶接トーチが移動を始めて から, 温度場が計測出来るようになるまでには一定の時間を 必要と寸る. 溶接電流を切断してから計測開始までの時間を, Fig. 7 で遅延時間 $T_{D}$ とした. 本実験装置における $T_{D}$ は, 約 $33 \mathrm{~ms}$ であった. このため, 本実験によって取得できる温 度場は，溶接中のものではなく，溶接電流を切断してから $30 \mathrm{~ms}$ 以後のものとなっている.

Fig. 6 の溶融池温度場の計測結果より，この実験ではプー ル表面における最高温度は約 $1800 \mathrm{~K}$ となっていることが分 かった。

なお，これらの溶融池温度場を比べると，電流が大きくな ると, 幅の広い溶融池が得られたが, 溶接電流の増加は溶融 池の最高温度に対してはそれほど影響しないようである。

\section{6. 硫黄含有量が溶融池温度場に及ぼす影響}

TIG 溶融池内での流動現象が母材金属に含まれる微量元 素の影響を受ける.このような振る舞いを起こす元素として
硫黄が良く知られている。ここでは, 硫黄含有量の違いが溶 融池温度場に及ぼす影響について示す。

Fig. 8 と Fig. 9 は, 硫黄含有量が異なる二種類の材料を TIG 溶融させた場合の溶融池温度場と溶込み形状を示している. 硫黄含有量が高い材料では, 同じ溶接電流で溶融させた場合 でも，硫黄含有量が低いものにくらべて溶込みが深くなって いる，また，硫黄含有量が高い材料では，図のようにプール 表面温度が高くなる傾向が見られる。

次に, 溶接電流切断後の冷却過程にある溶融池の温度場か ら，溶接中のプール最高温度を推定した結果を Fig. 10 に示 す.

補外による推定であるため，問題を残しているが，溶接中 の溶融池における最高温度もまた硫黄含有量の影響を受け ていることが予想される.

Fig. 10 より, 溶接中のプール最高温度は. 硫黄含有量が高 い材料の方が硫黄含有量の低いものに比べて約 $50 \mathrm{~K}$ 高い, 約 $2000 \mathrm{~K}$ であると推定される. 


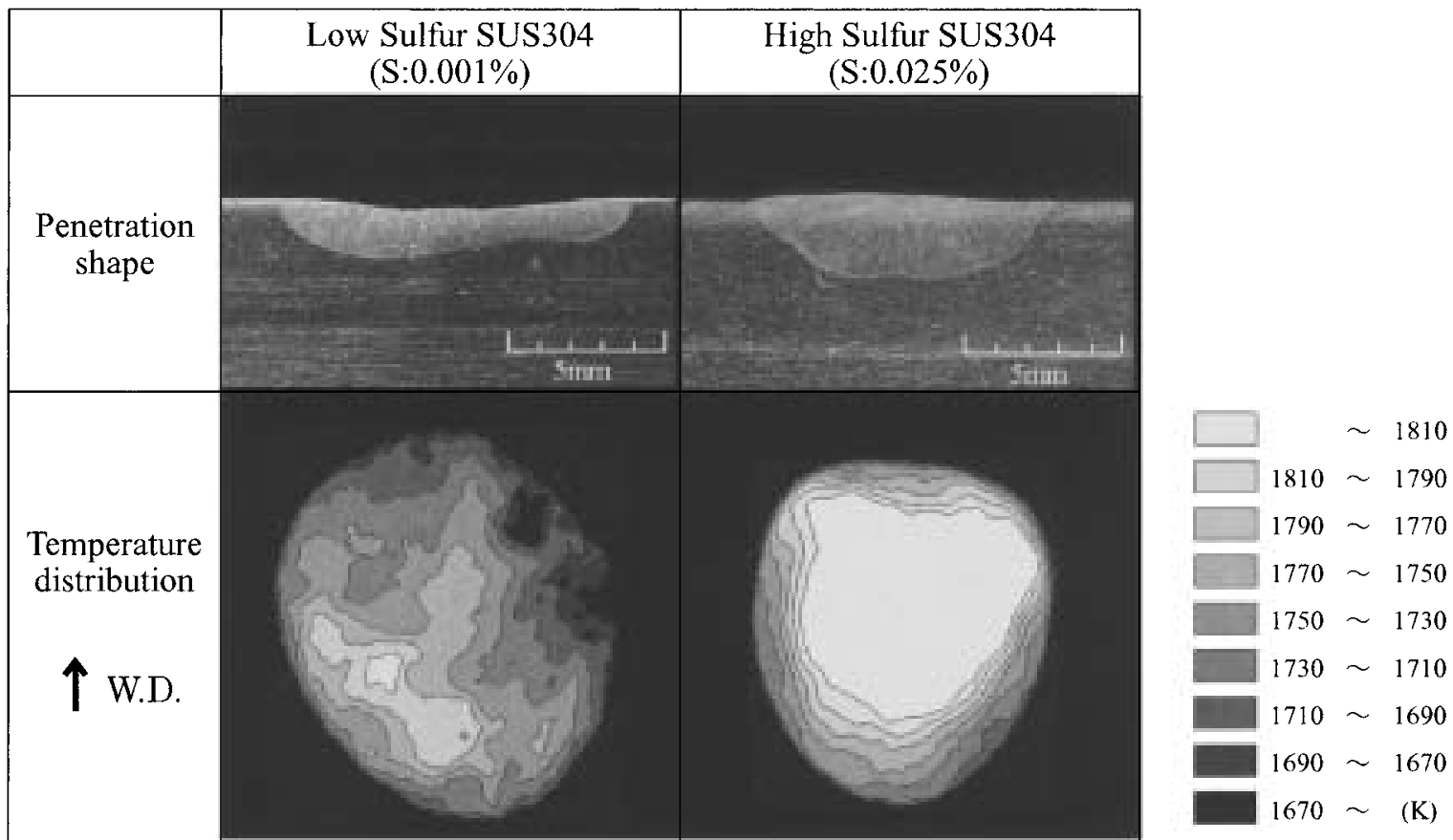

Fig. 8 Effect of sulfur on temperature distributions $\left(v=2.5 \times 10^{-3} \mathrm{~m} / \mathrm{s}, I=200 \mathrm{~A}\right.$, Exposure $120 \mathrm{~ms} 12 \mathrm{mmt}$, SUS304).

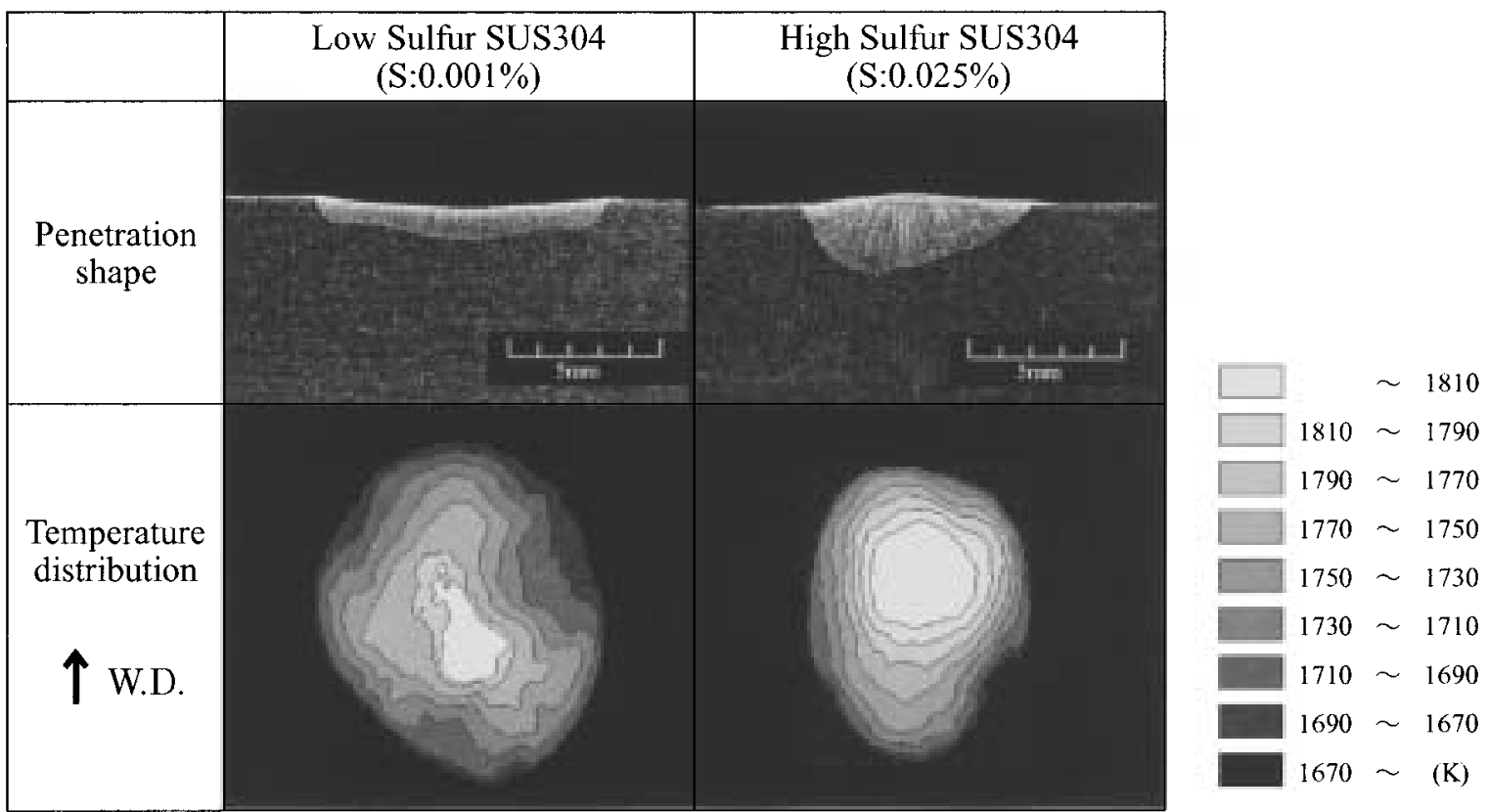

Fig. 9 Effect of sulfur on temperature distributions $\left(v=4 \times 10^{-3} \mathrm{~m} / \mathrm{s}, I=200 \mathrm{~A}\right.$, Exposure $120 \mathrm{~ms}, 12 \mathrm{mmt}$, SUS304).

\section{7. 結言}

放射測温法は, 計測に使用する波長を短くすることで, 放 射率による誤差の発生を抑制することができる. 本論文では, $\lambda=0.35 \mu \mathrm{m}$ の波長で計測を行う紫外線放射温度計を試作し， 溶融池温度場の計測を行った。以下に結果を示寸.

(1) 溶融池表面の放射率変動が激しい状況にあっても, 現行 の赤外線放射測温法に比べて, 正確な温度計測ができた.
(2) 母材金属に微量に含まれる硫黄含有量の差が, 明らかな 溶融池温度の差として現れることが分かった。

以上から, 本研究で提案した紫外線放射測温法は, 溶接現 象をより良く理解するためのツールとして期待できる.

なお, 現在使用している装置では溶接中の温度場を直接計 測することができない，溶接時の温度場を知るために，推定 方法や実験方法を考慮することがのぞまれる。

溶接中の溶融池温度場の推定・計測が可能となれば，より 良い計測手段として利用できるものと考えている. 


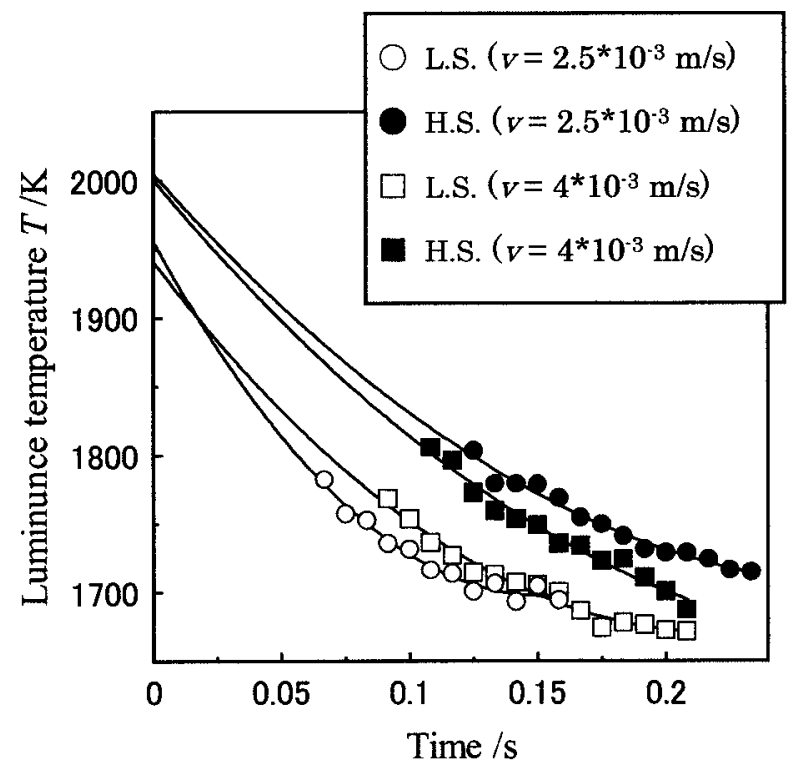

Fig. 10 Change of the peak surface temperature on metal pool.
謝辞

本研究は経済産業省重要地域技術開発制度の一環として, NEDO から JSUP を通じて委託された「溶接技術の高度化に よる高効率・高信頼性溶接技術の開発」の成果である.

\section{参 考 文 献}

1) D.P. DeWitt and G.D.Nutter, Theory and Practice of Radiation Thermometry, Wiley Interscience, (1988), 173.

2) M. Weiss, High Temperature Ultraviolet Radiometer, Instruments \& Control Systems, vol. 2, No.11, (1963), 1113.

3) T. Ohji, N. Yoshioka, T. Shiwaku, A. Ohkubo : Temperature measurement of UV thermal radiation, J. Jws, 12-3, (1994), 368-373.

4) 黄地, 佐藤, 藤井, 第 102 回温度計測部会資料, 計測自 動制御学会，（1997），18-28.

5) 計測自動制御学会・温度計測部会編:新編温度計測, 計測 自動制御学会, (1992), 第 4 章.

6) W.H. GIEDT, X-C.WEI, and S-R. WEI: Effect of Surface Convection on Stationary GTA Weld Zone Temperature, Weld. J., 63-12, (1984), 376s-383s. 